\title{
Regional productivity growth in the EU since 2000: Something is better than nothing
}

\author{
Nicky Rogge \\ Nicky.Rogge@kuleuven.be \\ KU Leuven, Faculty of Economics and Business, \\ Onderzoekseenheid ECON-CEDON \\ Warmoesberg 26, 1000 Brussels
}

\begin{abstract}
This paper examines productivity growth across NUTS 2-regions in the EU during the period in which the Lisbon Strategy was rolled out (period 2000-2011). A robust non-parametric production frontier estimation technique is used to estimate and decompose regional productivity growth. Results show that in spite of the increased focus on improving competitiveness and productivity in European programs such as the Lisbon Agenda, regional productivity growth has been relatively limited for the whole EU. However, behind the modest average regional growth rate, there are high interregional differences in growth rates. Results also show evidence of a limited convergence trend in the EU-region since 2000.
\end{abstract}

Keywords: Economic growth, Production frontier, Non-parametric analysis, European Union, NUTS2-regions. JEL-code: C14, C61, C67, E24, J24, O40, O52.

Corresponding author: Nicky Rogge, Katholieke Universiteit Leuven (KULeuven), Faculty of Economics and Business, Research Group ECON-CEDON, Warmoesberg 26, B-1000 Brussels, Tel.: +3226098257. 


\section{Introduction}

In the EU, during the past decades, the issue of regional economic growth and convergence has taken on particular significance. Not only have European policy makers continually highlighted the importance of regional economic growth for closing the 'competitiveness gap' with the US, more recently, with the Europe 2020-strategy, regional economic growth and convergence is increasingly indicated as essential for improving economic and social cohesion in the European Union and, hence, a successful European integration. The reason for this increase in policy focus on stimulating regional economic growth and convergence is the growing awareness among EU policy makers that a lack of convergence in economic productivity between regions may not only jeopardize the economic competitiveness of the EU as a global economic power but also could endanger the internal political, economic and social stability. In particular, as more dispersion in economic productivity and growth causes less developed regions to depend on support of more developed regions, the fear is that the presence of too large dispersions might disturb the balance of political power in the EU.

Together with ESI Funding, Cohesion and Regional policy investments are key instruments to realize smart, sustainable and inclusive growth. With the European Commission spending roughly one third of the EU Budget on Cohesion and Regional policy, with investments in the main drivers of economic growth: research and development, innovation, transportation, digital economy, energy security and efficiency, competitiveness of SMEs, and quality and accessibility of education, the question raises whether all these investments are helping EUregions to grow more quickly. In addition, as the bulk of the financial support of the Cohesion and Regional policy and the ESI-Funds is particularly going towards the less developed Member States and regions, another important query is whether or not this consistent focus on less developed regions has actually benefited convergence and cohesion among EU Member States and regions. In the literature there is still ambiguity on this question with some academics finding positive effects (Kutan and Yigit 2007), others finding mixed effects (e.g., Becker, Egger and von Ehrlich 2010), and other studies finding no considerable effects on cohesion in regional productivity (Delgado-Rodríguez and Álvarez-Ayuso 2008).

The present paper contributes to the literature by providing empirical evidence on regional economic growth and convergence in what has been an important period for the EU, i.e., the period 2000-2011 in which the Lisbon Strategy was rolled out. The paper estimates and analyses the productivity growth of the NUTS 2-regions in the EU over this period thereby using the latest update of regional productivity data as provided by Eurostat. In doing so, the paper attempts to provide answers to several policy-relevant research questions such as: (1) What was the evolution in labour productivity in the period 2000-2011?; (2) Was the productivity growth realized by NUTS 2-regions within the same Member State largely similar or was there considerable interregional disparity?; (3) Were the relative contributions of efficiency change, technological change, and changes in physical and human capital accumulation to productivity growth more homogeneous or rather heterogeneous across NUTS 
2-regions?; and (4) Was there a trend of convergence or rather one of divergence in regional productivity in the EU? ${ }^{1}$

The paper advocates the use of a non-parametric production frontier technique to study regional productivity growth. ${ }^{2}$ The reason is that, as compared to the traditional (parametric) techniques used predominantly in the economic growth and convergence literature (for studies on the EU, examples include Bartkowska and Riedl 2012; Battisti and De Vaio 2008; Juessen 2009; Azomahou, El ouardighi, Nguyen-Van and Pham 2011), non-parametric frontier methods make fewer and less strict assumptions in the modelling of the production frontier technology. In particular, whereas traditional techniques typically impose a specific 'functional form' of the production function (e.g., Cobb-Douglas production function, constant elasticity of substitution (CES) production structure, etc.) that characterizes the existent production technology, nonparametric techniques specify the production function a posteriori from the observed data themselves. Moreover, given that inefficiencies can exists under this non-parametric framework (contrary to most traditional techniques), there is also the possibility to examine how efficiency change contributes to productivity growth. Next to providing an estimate of productivity growth, the non-parametric frontier technique derives estimates on the different sources of productivity growth.

This paper also contributes to the ongoing policy discussions about the economic growth and convergence issue that is at the heart of the EU regional policy agenda. One particular contribution, as discussed in the previous paragraph, is that the paper provides empirical evidence on regional economic growth and convergence in the EU-area as derived from a nonparametric analysis framework. According to the advocates of non-parametric techniques (e.g., Färe, Grosskopf and Lovell 1994; Kumar and Russell 2002; Krüger 2003; Henderson and Russell 2005), this data-driven approach gives a more realistic framework to study productivity growth and convergence. A second contribution is that the paper explores regional differences in productivity and economic growth both within as well as between countries. This enables to identify whether changes in regional productivity have been relatively "even" or rather "uneven". Such information is useful for policy makers at the European level as it provides them with an idea on the impact of given regional financial support of the Cohesion and Regional policy and the ESI-Funds. On the other hand, such information is also valuable for national policy makers as it shows which regions require further policy intervention and/or support. Another contribution is that the paper identifies the different components of productivity growth. In particular, the non-parametric frontier technique estimates for each individual region the contributions of efficiency change, technological change, physical capital accumulation or human capital accumulation to economic growth. It is argued that

\footnotetext{
${ }^{1}$ Broadly speaking, the economic literature distinguishes between two types of convergence: $\beta$-convergence and $\sigma$-convergence. $\beta$-convergence refers to the process by which economies that were initially lagging in terms of productivity are growing faster and catching-up with economies that were already performing strongly. $\sigma$ convergence takes place when the dispersion in the productivity levels across economies is decreasing over time (for more on the types of convergence, see e.g. Durlauf and Quah 1999).

2 A parametric production frontier technique that has been employed in the estimation of TFP-growth is the Stochastic Frontier Analysis (see, e.g., Kumbhakar and Wang 2005; Kumbhakar and Sun 2012). For a detailed comparison of parametric and non-parametric production frontier estimation techniques, see Hjalmarsson, Kumbhakar and Heshmati (1996).
} 
differentiating between the components of productivity growth is important particularly from the perspective of designing effective policies. It helps policy makers to reach informed decisions about which type of policies are most suitable for each region (given that they are typically subject to different economic, social and cultural conditions).

The paper is organized as follows. Section 2 discusses the main outcomes of previous empirical studies on regional productivity growth in the EU. Section 3 describes the non-parametric methodology that is used in the present paper to estimate and analyze regional productivity growth. Section 3 presents the regional (macro)economic data for the NUTS 2-regions in the EU for the period 2000-2011. Section 4 presents the results. Finally, Section 5 concludes and formulates several interesting topics for further research.

\section{Earlier research on regional growth in $\mathbf{E U}$}

Earlier studies on the regional growth in the EU demonstrated the existence of slow growth and a slow process of convergence. Sala-i-Martin and Barro (1991) employed a (parametric) autoregressive model to investigate regional convergence within 8 Northern EU Member States (the six original Member States and Denmark and the UK) using economic data on 73 regions for the period 1950-1985. The estimations revealed a slow process of conditional convergence (speed of convergence of approximately 1.8\%). Neven and Gouymte (1995) employed a mix of autoregressive and Markov chain models to examine regional convergence for the period 1975-1990, thereby using data on aggregate output per head for 108 regions for the period 19751980 and 142 regions for the period 1980-1990. One consistent finding was that the pattern of convergence differed considerably across subsets of regions and across different periods. Whereas in the early 1980s the pattern among the Northern regions was more one of stagnation or (slight) divergence, the second part of the eighties was more one of convergence. Among the more Southern EU-regions, on the other hand, a trend of convergence was found in the first part of the 1980s followed by a period of stagnation in the second part. De Siano and D'Uva (2006) applied tests on stochastic convergence on regional economic data for 123 regions belonging to $9 \mathrm{EU}$ Member States for the period 1981-2000. The test for stochastic convergence revealed empirical evidence of club convergence with a strong tendency of convergence among the wealthiest regions and a trend of weak convergence among the remaining groups of EUregions. Using a predictive density approach with roots in Bayesian econometrics, Canova (2004) examined regional economic growth in the EU thereby testing for convergence among 144 European NUTS 2-regions for the period 1980-1992. Results showed evidence for convergence poles characterized by different economic conditions. Crespo Cuaresma, Doppelhofer and FeldKircher (2014) employed a Bayesian Model Averaging approach to explore the determinants of regional economic growth of 255 NUTS 2-regions during the period 1995-2005, thereby accounting for the potential presence of spatial interaction among the regions. Results pointed out the presence of convergence, with an estimate of the speed of convergence of around $2 \%$. However, as indicated by the authors, this estimate is largely influenced by the changes in growth experienced by the regions in the Central and Eastern European Member States. In particular, the growth rates experienced by the regions in the Central and Eastern European Member States were generally higher than the ones realized by 
the other regions. Beugelsdijk, Klasing and Milionis (2015) investigated the within-country differences in economic development across Europe using a development accounting approach. Results indicated, amongst other things, very large productivity differences between the NUTS 2-regions and the presence of large within-country interregional productivity differences. Azomahou, El Ouardighi, Nguyen-Van and Pham (2011) explored productivity dynamics across EU-regions using a semi-parametric partially linear model. Estimations were made for two sets of NUTS 2-regions, one set including data on 157 regions from 9 EU countries for the period 1990-2005 and another set with data from 255 regions for 20 EU countries for the period 1998-2007. A consistent finding was heterogeneity in the convergence process with a trend of divergence among regions with low initial GDP per capita levels (low-income regions from new EU Member States), a trend of convergence among regions with medium initial levels of GDP per capita levels and no outspoken trend among the richest EU-regions. Estimation results also pointed out country heterogeneity and nonlinearity in the convergence process. Becker, Egger and von Ehrlich (2016) used a regression discontinuity design framework to analyze regional growth in the EU during four consecutive programming periods (1989-1993, 19941999, 2000-2006 and 2007-2013) with a special focus on the effects of Objective 1 transfers. Results showed that EU regional transfers did generate additional growth across regions in the EU, the effects being somewhat stronger during the two first periods as compared to the two most recent programming periods.

In sum, a recurrent finding in past studies on regional productivity growth dynamics in the EU was the existence of a slow process of convergence. The estimates of speed of convergence found in these studies were all situated around 1\%-2\% per annum. A second important finding was that the pattern of convergence differed considerably across subsets of regions and across different time periods. Thirdly, as can be noted in the short review of the empirical literature, a large majority of the techniques that have been applied by previous studies are parametric in nature. ${ }^{3}$ As denoted above, particularly problematic to the need of parametric models to presume rather stringent assumptions is that there is typically a lot of uncertainty about the validity of the assumptions and, hence, a potential issue of model misspecification. The remainder of this paper advocates the use of a non-parametric production frontier estimation techniques after Färe et al. (1994), Kumar and Russell (2002), Henderson and Russell (2005), and Badunenko, Henderson and Russell (2013) to estimate and analyse the dynamics in regional productivity growth in the EU. The next section describes this technique in detail.

\section{Methodology}

\section{Sequential production frontier technology}

The regional productivity is measured using three input variables and one output variable. The output variable $Y_{j, t}$ is the aggregate output of the region $j(j=1, \ldots, N)$ in the year $t(t=$ $1, \ldots, T)$. The three input measures are labour $L_{j, t}$, physical capital $K_{j, t}$, and human capital $H_{j, t}$.

\footnotetext{
${ }^{3}$ Note that earlier studies that examine regional economic growth and convergence in the US (e.g., across US states) also mostly use parametric techniques (e.g., Christopoulos and Tsionas 2007; Drivas, Economidou and Tsionas 2017; Tsionas 2000; Tsionas 2001).
} 
Following the recent production frontier studies (e.g., Badunenko et al. 2013) and the (macro)economics literature (see, e.g., Mankiw, Romer and Weil 1992), the standard assumption is made that human capital augments the physical labour input by a multiplication. This yields human capital augmented labour $\hat{L}_{j, t}=L_{j, t} H_{j, t}$. It represents the labour input measured in efficiency units for the region $j$ in year $t$. By this assumption, the three input - one output setting is reduced to a two input - one output setting.

To determine the production frontier technology, an estimation methodology after Charnes, Cooper and Rhodes (1978) is used. This method is linked to the earlier work of Koopmans (1951), Farrell (1957) and Afriat (1972) on Activity Analysis and linear programming models for economic analysis. The key feature of this technique is that it estimates the production frontier in a non-parametric way, i.e., without assuming any functional format that characterizes the existent production frontier technology. Instead, this method defines the production frontier in a data-driven manner thereby building upon very general axioms of economic production theory (additivity, no free lunch, free disposability, and homogeneity of degree one. For more on the axioms see Fried, Lovell and Schmidt, 2008).

In the present analysis, a sequential version of this non-parametric frontier method as originally introduced by Diewert (1980) is used to specify the production frontier of the NUTS 2-regions. This version was also applied in previous studies examining country-level productivity growth (e.g., Henderson and Russell 2005; Badunenko et al. 2013). This approach constructs the production technology $\Psi_{t}$ in year $t$ using the regional production data for the year $t$ and all the previous years (i.e., $\tau=1, \ldots, t)$. This presumes an interdependence between production technology over time with the production technology in year $t$ not only comprising technological innovations that were realized in year $t$ but also the technological knowledge that was already obtained in the past. By this assumption, technological degradation is impossible. More formally, under the assumption of constant returns to scale, the sequential production set, i.e. the set of all feasible input-output combinations, is specified as follows:

$$
\Psi_{t}=\left\{\begin{array}{l|l}
\langle, \hat{L}, K\rangle \in \mathfrak{R}_{+}^{3} & \begin{array}{c}
Y \leq \sum_{\tau \leq t} \sum_{j=1}^{N} \lambda_{j, \tau} Y_{j, \tau} \\
s . t . \\
\hat{L} \geq \sum_{\tau \leq t} \sum_{j=1}^{N} \lambda_{j, \tau} \hat{L}_{j, \tau} \\
K \geq \sum_{\tau \leq t} \sum_{j=1}^{N} \lambda_{j, \tau} K_{j, \tau} \\
\lambda_{j, \tau} \geq 0 \\
(j=1, \ldots, N ; \tau=1, \ldots, t)
\end{array}
\end{array}\right\}
$$

With $\lambda_{j, \tau}$ the activity levels indicating how relevant other (observed) regions are for constituting the benchmark against which the efficiency of the region $j$ in year $\tau(\tau=1, \ldots, t)$ is to be assessed (i.e., the intensity variables from Activity Analysis used to transform data points in the sample into a production technology set). 


\section{Productivity growth and quadripartite decomposition}

The Farrell output-oriented efficiency measure (Farrell 1957) is used to estimate the efficiency of region $j$ in realizing aggregate output using the disposable inputs and the sequential production technology $\Psi_{t}$. For region $j$ in year $t$, this output efficiency measure is obtained as follows:

$$
e_{j, t}=\min \left\{\lambda \mid\left\langle Y_{j, t} \mid \lambda, \hat{L}_{j, t}, K_{j, t}\right\rangle \in \Psi_{t}\right\}
$$

The inverse of $e_{j, t}$ specifies the maximal proportional expansion possible in the aggregate output of region $j$ in year $t$ given the input levels in year $t$ and the, at that moment, available production technology $\Psi_{t}$. The output efficiency measure can take values lower than or equal to one. A value lower than one indicates that region $j$ can expand its aggregate output given the used inputs and available production technology. The value also specifies the proportion with which region $j$ should expand the aggregate output in order to become positioned at the production frontier. A value for the output efficiency measure equal to one specifies that region $j$ is positioned on the production frontier and, hence, realizes the benchmark level of aggregate output that is technologically feasible given the employed inputs and the available production technology.

In the setting of estimating regional productivity change, regional output efficiency measures can be determined relative to the sequential production frontiers of the base period and the current period (i.e., $e_{j, b}$ and $e_{j, c}$ ). Both efficiency measures enable defining the benchmark levels for the aggregate output of region $j$ for the respective periods: $\bar{Y}_{j, b}=Y_{j, b} / e_{j, b}$ and $\bar{Y}_{j, c}=$ $Y_{j, c} / e_{j, c}$. Taking the ratio of the output efficiency measures and the associated benchmark levels for the aggregate output of region $j$ for the current and base periods yields the productivity growth measure as in (3):

$$
\frac{Y_{j, c}}{Y_{j, b}}=\frac{e_{j, c}}{e_{j, b}} \frac{\bar{Y}_{j, c}}{\bar{Y}_{j, b}}
$$

In order to get a better idea on the different components of productivity growth, several transformations of the input and output data are implemented. Firstly, the aggregate output per unit of physical labour (i.e., average labour productivity) using base period and current period data are defined as $y_{j, c}=Y_{j, c} / L_{j, c}$ and $y_{j, b}=Y_{j, b} / L_{j, b}$. Secondly, the aggregate output and physical capital levels per unit of human capital augmented labour for the region $j$ in the current period and base period are specified as $\hat{y}_{j, c}=Y_{j, c} / \hat{L}_{j, c}, \hat{y}_{j, b}=Y_{j, b} / \hat{L}_{j, b}, \hat{k}_{j, c}=K_{j, c} / \hat{L}_{j, c}$ and $\hat{k}_{j, b}=K_{j, b} / \hat{L}_{j, b}$. Using $\hat{y}_{j, c}, \hat{y}_{j, b}, \hat{k}_{j, c}$, and $\hat{k}_{j, b}$, the benchmark aggregate output level for the region $j$ per human capital augmented unit of labour can be determined for the base period and current period data, i.e. $\bar{y}_{j, b}\left(\hat{k}_{j, b}\right)=\hat{y}_{j, b} / e_{j, b}$ and $\bar{y}_{j, c}\left(\hat{k}_{j, c}\right)=\hat{y}_{j, c} / e_{j, c}$. In addition, ratios of the physical capital in the current period (base period) to units of human capital augmented labour in the current period (base period) determined under the counterfactual presumption that human capital is of the level such as in the base period (current period), i.e. $\tilde{k}_{j, c}=$ $K_{j, c} /\left(L_{j, c} H_{j, b}\right)$ and $\tilde{k}_{j, b}=K_{j, b} /\left(L_{j, b} H_{j, c}\right)$. Using these adjusted versions of physical capital, 
alternative definitions of the benchmark aggregate output levels for country $j$ in the base period and current period can be specified: $\bar{y}_{j, b}\left(\tilde{k}_{j, b}\right)$ and $\bar{y}_{j, c}\left(\tilde{k}_{j, c}\right)$. Implementing the aforementioned transformations in the productivity growth ratio of region $j$ as in (3) gives two possible decompositions, i.e., $(4 a)$ and $(4 b)$ :

$$
\begin{gathered}
\frac{y_{j, c}}{y_{j, b}}=\left(\frac{e_{j, c}}{e_{j, b}}\right) \times\left(\frac{\bar{y}_{j, c}\left(\hat{k}_{j, c}\right)}{\bar{y}_{j, b}\left(\hat{k}_{j, c}\right)}\right) \times\left(\frac{\bar{y}_{j, b}\left(\tilde{k}_{j, c}\right)}{\bar{y}_{j, b}\left(\hat{k}_{j, b}\right)}\right) \times\left[\frac{\bar{y}_{j, b}\left(\hat{k}_{j, c}\right)}{\bar{y}_{j, b}\left(\tilde{k}_{j, c}\right)} \cdot \frac{H_{c}}{H_{b}}\right] \\
\frac{y_{j, c}}{y_{j, b}}=E F F_{j} \times T E C H_{j}^{c} \times K A C C_{j}^{b} \times H A C C_{j}^{b}
\end{gathered}
$$

and

$$
\begin{gathered}
\frac{y_{j, c}}{y_{j, b}}=\left(\frac{e_{j, c}}{e_{j, b}}\right) \times\left(\frac{\bar{y}_{j, c}\left(\hat{k}_{j, b}\right)}{\bar{y}_{j, b}\left(\hat{k}_{j, b}\right)}\right) \times\left(\frac{\bar{y}_{j, c}\left(\hat{k}_{j, c}\right)}{\bar{y}_{j, c}\left(\tilde{k}_{j, b}\right)}\right) \times\left[\frac{\bar{y}_{j, c}\left(\tilde{k}_{j, b}\right)}{\bar{y}_{j, c}\left(\hat{k}_{j, b}\right)} \cdot \frac{H_{c}}{H_{b}}\right] \\
\frac{y_{j, c}}{y_{j, b}}=E F F_{j} \times T E C H_{j}^{b} \times K A C C_{j}^{c} \times H A C C_{j}^{c}
\end{gathered}
$$

The first term in the decomposition is the efficiency change $\left(E F F_{j}\right)$-component for region $j$. It measures the progress (regress) in the productivity growth realized by the region's own idiosyncratic performance. More precisely, this component measures whether the region $j$ was able to catch-up (or whether it fell back) to the productivity frontier. An $E F F_{j}$-value higher than one indicates that region $j$ was able to catch-up with the productivity frontier. An $E F F_{j}$-value lower than one denotes that region $j$ fell back to the productivity frontier. A value of unity indicates the status quo, i.e. no change in the productivity of region $j$ vis-à-vis the benchmark level of productivity as determined by the productivity frontier. The second component in the decomposition is the technological change $\left(\mathrm{TECH}_{j}\right)$-component for region $j$. This component captures the diffusion of production technology and innovation among EU-regions. In the present analysis, $T E C H_{j}$-values can be higher than or equal to one. A $T E C H_{j}$-value higher than one reflects a shift outward of the productivity frontier suggesting an improvement in the available production technology during the period of study enabling higher productivity levels, all else equal. A $T E C H_{j}$-value equal to one reflects that the productivity frontier remained unchanged. The third component is the physical capital accumulation component for region $j$ $\left(K A C C_{j}\right)$. It measures the effect of physical capital accumulation respectively along the productivity frontier of the base period in $(4 a)$ and the current period in $(4 b)$. Somewhat similarly the fourth component in $(4 a)$ and $(4 b)$ measures human capital accumulation for region $j\left(H A C C_{j}\right)$ along the productivity frontier of the base period and the current period.

Given that the two productivity change measures as in $(4 a)$ and $(4 b)$ will usually have different values, to avoid any arbitrariness in the computations, Färe, Grosskopf and Lovell (1994) suggested to calculate the productivity change as the geometric mean of the measures to obtain (5) (also known as the "Fisher ideal" index). The interpretation of the components and the component values remains unaltered by this adjustment. 


$$
\frac{y_{j, c}}{y_{j, b}}=E F F_{j} \times\left[T E C H_{j}^{b} \cdot T E C H_{j}^{c}\right]^{1 / 2} \times\left[K A C C_{j}^{b} \cdot K A C C_{j}^{c}\right]^{1 / 2} \times\left[H A C C_{j}^{b} \cdot H A C C_{j}^{c}\right]^{1 / 2}
$$

Before concluding, note that, in the estimations, a robust (order- $m$ ) version of the nonparametric frontier estimation technique is used (Cazals, Florens and Simar 2002). The reason is that non-parametric frontier estimation techniques such as the one presented above are deterministic in nature, which means that the position and the shape of the estimated production frontier and, hence, the estimations and decompositions of the regional productivity growth rates are sensitive to regions with macroeconomic data that are atypical and/or outlying. The essential idea of the robust approach is to develop a robust specification of the production frontier under a simple bootstrapping framework in which a high number of runs are performed (in casu 1,000), in each of which a sub sample of regions (randomly and i.i.d. drawn from the full sample) are used in the specification of the production frontier. As regions with atypical and/or outlying macroeconomic data do not form part of the sub sample in every draw, the impact of such regions on the estimations of the quadripartite decomposition of productivity growth is effectively mitigated.

\section{Multimodality and component analysis}

Multimodality or the existence of several peaks in the distribution of the regional productivity can be seen as an indication of the existence of regional heterogeneity (Badunenko et al. 2013). To determine the modality of the distributions of the aggregate output per worker as in 2000 and 2011 as well as the counterfactual distributions of the aggregate output per worker as constructed by a stepwise introduction of the four different productivity growth components or combinations of these components, non-parametric multimodality tests are performed by the bootstrapped Silverman test for multi-modality (Silverman 1981; Hall and York 2001). The null hypothesis in the Silverman test is that the distribution of the output per worker has at most $\gamma$ modes $\left(\mathrm{H}_{0}\right.$ : number of modes $\left.\leq \gamma\right)$. The alternative hypothesis is that this distribution has more than $\gamma$ modes $\left(\mathrm{H}_{1}:\right.$ number of modes $\left.>\gamma\right)$. The test uses 10,000 bootstrap replications to compute the $p$-value as the frequency that the critical bandwidth of the bootstrap sample is larger than the critical bandwidth of the given data (which suggests that sample data has more than $\gamma$ modes). If the returned $p$-value is smaller than the given level of significance (i.e., 0.05) the null hypothesis is rejected and the alternative hypothesis is adopted.

We also test for the statistical significance of the contributions of the different individual components of productivity growth or combinations of these components to the convergence in regional productivity between 2000 and 2011. In particular, we use the non-parametric test of Fan and Ulla (1999) (after a test initially proposed by Li 1996) to compare two unknown distributions, i.e. the estimated and counterfactual distributions. The null hypothesis is that the estimated distribution $f($.$) and the counterfactual distribution g($.$) are equal, i.e. H_{0}: f()=$. $g($.$) . The alternative hypothesis is that the estimated and counterfactual distributions are$ statistically significantly different, $H_{1}: f()=.g($.$) . The idea is that a confirmation of the$ 
$H_{0}$ denotes that the relative contribution of the included productivity change component is not statistically significant. The opposite holds for when the test rejects the $H_{0}$. In that case, the estimated and counterfactual distribution do differ statistically significantly which implies that the relative contribution of the productivity change component to the overall productivity change is statistically significant (for more on formalities of the test, the interested reader is referred to Fan and Ulla 1999; Badunenko et al. 2008).

\section{Regional (macro)economic data}

The data for the three macroeconomic input variables and the aggregate output for the period 2000-2011 are collected from the Regional Database published by Eurostat. The definition of the NUTS 2-regions is according to the Nomenclature of Territorial Units for Statistics classification system of the European Parliament. In the NUTS 2-classification system there are six countries which have no underlying NUTS 2-regions due to their limited size: Lithuania, Malta, Cyprus, Latvia, Estonia, and Luxembourg. For these countries, the national data are used. The final sample set includes 336 NUTS 2-regions (i.e., $N=336$ ).

The aggregate output $\left(Y_{j, t}\right)$ is measured by the regional gross domestic product (GDP) at constant market prices, in million euro PPS. The input labour $\left(L_{j, t}\right)$ is measured by the variable 'economically active population by highest level of education attained'. Data on the physical capital stock $\left(K_{j, t}\right)$ are not available in the Regional Database of Eurostat. Estimations for the physical capital stock are therefore obtained from an application of the Perpetual Inventory Method (PIM) (Feldstein and Foot 1971; Epstein and Denny 1980) using regional investment data (available in the Regional Database). The PIM-formulation is as follows: $K_{j, t}=I_{j, t}+$ $(1-\delta) K_{j, t-1}$, where $K_{j, t}$ and $K_{j, t-1}$ are the gross capital stock of region $j$ in year $t$ and $t-1$; $I_{j, t}$ is the gross fixed capital formation in region $j$ between year $t-1$ and year $t$, and $\delta$ represents the depreciation rate of the physical capital stock (here $\delta$ is set equal to $6 \%$ similar to in most previous studies, e.g., Badunenko et al. 2013). In the computations, the regional gross fixed capital formation was converted into constant prices PPS using a (country-level) GDP deflator and a relative price factor (PPS) as obtained through a comparison of regional GDP in current and constant prices. The PIM-method requires an initial value of the physical capital stock $\left(K_{j, 0}\right)$ in order to compute the time series of regional physical capital stock. To estimate this starting value, following the approach of Beugelsdijk et al. (2015), regional real investment data is backwardly extrapolated up to the starting year of the time series (i.e., the year 1970) so as to derive an estimate of the regional physical capital stock in that year. Using this estimate of $K_{j, 0}$, time series data of the physical capital stock for the regions are developed from which the data for the period 2000-2011 are used in the present study (for more details, see Beugelsdijk et al. 2015 p. 8-9).

To estimate the human capital of the labour force, data on the distribution of the region population by education attainment are used (ISCED 0-2: pre-primary, primary, lower secondary education; ISCED 3-4: upper secondary, post-secondary non-tertiary education; ISCED 5-6: $1^{\text {st }}$ and $2^{\text {nd }}$ stage of tertiary education). The actual adjustment of the labour force 
for human capital is performed according to Hall and Jones (1999). In particular, human capital augmented labour is estimated by $\hat{L}_{j, t}=L_{j, t} . H_{j, t}=L_{j, t} \cdot \exp ^{\phi\left(\varepsilon_{j, t}\right)}$, with $\phi($.$) being a piece-$ wise linear function with zero intercept and slopes equal to $0.134,0.101$, and 0.068 for human capital obtained respectively during the first four years of schooling, the next four years and education years beyond the eighth year (for more details, see Beugelsdijk et al. 2015).

Figure 1 displays the production technology frontiers as computed by the above discussed sequential production frontier approach for the years 2000 and 2011 in a two-dimensional $\langle\hat{y}, \hat{k}\rangle$-space, which is readily derived from the initial three-dimensional $\langle Y, \hat{L}, K\rangle$-space by the following transformations: $\hat{y}=Y / \hat{L}$ and $\hat{k}=K / \hat{L}$. The figure show only minor differences in the shape and position of the frontiers in 2000 and 2011, with differences being situated at the higher levels of capital per efficiency unit of labour. This finding of technical change occurring mostly at higher levels of capitalization (non-neutrality of technological change) confirms what was found by previous studies for country-level data (Henderson and Russell 2005; Badunenko et al. 2013). A detailed study of Figure 1 also shows that both the position and the shape of the production frontier is predominantly determined by three atypical/outlying regions, i.e. Région de Bruxelles-Capitale, Luxembourg, and Inner London. With very high levels of aggregate output per efficiency unit of labour these three regions determine the upper part of the production frontiers in both 2000 and 2011. The presence of these three regions is a prima facie reason for using a robust version of the production frontier technique.

$<$ Figure 1 about here >

\section{Empirical findings}

Figure 2 displays the kernel distributions of the regional productivity and efficiency levels in the years 2000 (black solid curve) and 2011 (grey dashed curve). The vertical black solid line and grey dashed line in the plots represent the median regional productivity and efficiency values in the respective years. Some interesting preliminary findings emerge from these plots. Firstly, the plot in the left part of Figure 2 clearly shows that the distributions of regional productivity as in 2000 and 2011 are multimodal (peaks at levels of output per worker around 30,000 and 55,000) with some differences in the shape of the distributions and in both cases a long right-hand tail. Secondly, the median values of the regional productivity in 2000 and 2011 indicate a very small decline to almost no change during the period of study. Thirdly, the plot in the right part of Figure 2 shows that the kernel distribution of the regional efficiency as in 2000 is more situated to the right and hence at higher levels of efficiency as compared to the distribution in 2011. In addition, the median value of the regional efficiency in 2000 is considerably higher than the regional efficiency in 2011. This suggests that there has been a general decline in regional efficiency during the first decade of the $21^{\text {st }}$ century.

$<$ Figure 2 about here > 
The mean values of the regional productivity growth rates and the four components per EU Member State are listed in Table 1. ${ }^{4}$ Several interesting findings emerge from this table. Firstly, the mean values for all EU-regions listed at the bottom of Table 1 show that, on average, regional productivity slightly increased $(+2.79 \%)$ in the EU over the period 2000-2011. Results suggest that this increase was mainly because of positive changes in physical capital and human capital accumulation $(+14.89 \%$ and $+6.85 \%)$ in the regions outbalancing the negative regional efficiency change (-14.66\%). Overall, technological change was negligible (-0.05\%). A second interesting finding is that several Member States saw all of their regions realizing positive productivity growth rates over the period 2000-2011. Examples include the Czech Republic, Denmark, Germany, Croatia, Lithuania, Estonia, Slovakia, and Finland. The regions in Germany, for instance, realized growth rates ranging from a minimum of $+7.57 \%$ to a maximum of $+27.39 \%$. Thirdly, the mean values for the productivity change index, (TFP-1) x 100, indicate regress in productivity for the majority of the regions in Greece $(-10.16 \%)$, Italy $(-12.86 \%)$, Spain $(-8.74 \%)$, UK (-12.05\%), Hungary (-12.89\%), and Romania (-44.47\%) in the period 2000-2011. A possible explanation for this finding is that these Member States were hit comparatively hard by the consequences of the economic downturn in the second part of the period (as pointed out by the Sixth Cohesion Report, European Commission 2014). A fourth interesting finding is that several old EU Member States (e.g., Belgium, Denmark, Greece, Spain) and new EU Member States (Bulgaria, Hungary, Romania) saw all regions experiencing negative efficiency growth (i.e., $(E F F-1) \times 100<0)$ in the period 2000-2011. Only Germany $(+2.46 \%)$, Croatia $(+4.02 \%)$ and the Czech Republic $(+4.68 \%)$ realized on average positive regional efficiency change. This finding of decline in efficiency in the large majority of the regions during the first decade of the $21^{\text {st }}$ century seems somewhat at odds with the typical mantra of European economic integration being advantageous in terms of higher efficiency and increased competition. It is not straightforward to give a coherent explanation for this finding. However, a plausible explanation is the negative impact of the financial and economic crisis with a decline in aggregate demand and supply (i.e., lower regional aggregate output levels) and, by result, a regress in the production efficiency. A fifth interesting result is that technological change contributed almost not (i.e., $(E F F-1) \times 100 \approx 0$ ) to regional productivity growth over the period 2000-2011. Part of the explanation may well be related to the negative impact of the crisis in Europe with adopted (austerity) policies in most EU Member States placing more pressure on national and regional budgets, thereby limiting funding availability across all investment areas. The Sixth Report on Economic, Social and Territorial Cohesion (European Commission 2014) speaks of a decline of roughly 20\% in public investment between 2008 and 2013 for the EU as a whole and of around 60\% for the Southern European Member States (e.g., Greece and Spain). Finally, overall, physical capital and human capital accumulation contributed positively to regional productivity growth (mean values of $(K A C C-1) \times 100$ and $(H A C C-1) \times 100$ equal to $+14.89 \%$ and $+6.85 \%)$. As to the magnitude of these positive contributions, results suggest important differences between the regions in the old and new EU Member States. More precisely, as for the contribution of physical capital accumulation to regional productivity growth, the mean change values of

\footnotetext{
${ }^{4}$ The productivity growth rates and the quadripartite decomposition computed for the individual NUTS 2-regions are available from the author upon request.
} 
respectively $+8.04 \%$ and $+21.74 \%$ for the regions in the old and the new EU Member States clearly indicate a more significant contribution in the new EU Member States. Particularly remarkable are the strong contributions of the physical capital accumulation component in Bulgaria $(+58.15 \%)$ and Lithuania $(+67.37 \%)$. As for the human capital accumulation component (i.e., column ' $(H A C C-1) \times 100$ ' in Table 1$)$, results indicate a generally positive contribution to regional productivity growth in all old EU Member States and all but two new EU Member States (exceptions are Croatia and Lithuania). Note, however, that there are considerable differences across regions and/or Member States, with Member States such as Ireland (+16.68\%), Luxembourg (+23.61\%), Spain $(+16.97 \%)$, and Malta $(+14.55 \%)$ showing high positive contributions and regions in Member States such as Denmark $(+0.19 \%)$, Latvia $(+2.30 \%)$ and Romania $(+1.72 \%)$ experiencing on average only low contributions of human capital accumulation. As a possible explanation, Crespo Cuaresma et al. (2014) referred to the large variation in education systems across Member States and regions.

$<$ Table 1 about here >

Figure 3 visualizes the relationship between the initial regional productivity levels (i.e., output per worker in 2000) and the four productivity growth components. The plots reveal that all but one components relate statistically significantly to the initial regional productivity level. For the period 2000-2011, overall, technological change and physical capital accumulation are found to relate statistically significantly negatively (i.e., $p$-values for the slope coefficients of the fitted regression lines of respectively 0.044 and 0.000 ) and human capital accumulation statistically significantly positively $(p$-value $=0.000$ ) to the regional productivity as in 2000 . Only the efficiency change component is found to relate statistically insignificantly ( $p$-value of 0.614 ) to the regional productivity as in 2000. The positive changes in efficiency experienced by some regions more or less outbalanced the negative changes in efficiency seen in other regions. As to the finding of significant negative relationship for the technology change component, a brief look at the TECH-index values on the vertical axis reveals that although statistically significant, the relationship of technological change to initial regional productivity is trivial. The finding of a negative association between the contribution of physical capital accumulation to productivity growth and the initial level of regional productivity, indicates that, in general, physical capital accumulation contributed more strongly to productivity growth for regions with lower initial levels of aggregate output per worker. An opposite pattern is found for the relation between human capital accumulation and initial regional productivity, i.e., regions that were more productive in 2000 having benefited more from human capital accumulation as compared to the regions that were initially less productivity. Overall, these finding suggests that physical capital accumulation advanced and human capital accumulation hampered convergence among regions over the period 2000-2011, with initially less productive regions having benefited more from physical capital accumulation, yet, less from human capital accumulation as compared to the regions that were more productive in 2000.

$<$ Figure 3 about here > 
As to the multimodality of the distributions of regional productivity and the relation to the productivity components, the outcomes of the bootstrapped Silverman's tests are reported in Table 2. For the actual and counterfactual distributions three Silverman tests were computed by setting $\gamma$-values equal to respectively 1,2 and 3 . The test results demonstrate that the distributions of regional productivity as in 2000 and 2011 are multimodal with the distribution in 2000 displaying 3 modes and the distribution in 2011 showing 2 modes. This result confirms to some extent what was found by previous studies (Gitto and Mancuso 2015; De Siano and D'Uva 2006), i.e., the shape of the kernel distribution of the regional productivity having multiple modes. As indicated in the discussion of Figure 2, the two consistent peaks in the distribution of regional productivity are situated at levels of output per worker around 30,000 and 55,000. A screening of the outcomes of the modality tests for the different counterfactual distributions in Table 2 indicates that the introduction of the technological change and the physical capital accumulation component, individually or in combination, doesn't significantly impact the modality of the distribution of regional productivity. The shift in modality in the distribution of regional productivity from 2000 to 2011 is predominantly because of the human capital accumulation component.

\section{$<$ Table 2 about here >}

Table 3 displays the outcomes of the non-parametric method of Fan and Ullah (1999) to test for the statistical significance of the contributions of the four components of productivity growth and combinations of these components to mean preserving changes in the distribution of regional productivity. The first test in Table 3 indicates that the actual distributions of aggregate output per worker as in 2000 and 2011 differ statistically significantly ( $p$-value $<0.05$ ). This finding raises the question of what productivity components contributed significantly to the change in the distribution of aggregate output per worker over the period 2000-2011. With $p$ values near to zero the test outcomes reject the notion of efficiency change, technological change and physical capital accumulation being individually responsible for moving from the distribution in regional productivity as in 2000 to 2011 . The exception is the human capital accumulation component. With a $p$-value of 0.079 for the counterfactual productivity distribution accounting solely for the human capital accumulation and of 0.225, 0.078, 0.226, and 0.120 for the counterfactual productivity distributions with combinations of productivity components including the human capital accumulation component, the test outcomes suggest that the accumulation in human capital contributed considerably to the change in the distribution of regional productivity during the period 2000-2011. ${ }^{5}$

$<$ Table 3 about here >

\footnotetext{
${ }^{5}$ Testing the relative contributions of the components for changes in the sequence in which the components are added indicate that the test results are not sensitive to the sequence.
} 


\section{Concluding remarks and suggestions for further research}

The paper examined multiple policy-relevant research questions: (1) What was the evolution in labour productivity in the period 2000-2011?; (2) Was the productivity growth realized by NUTS 2-regions within the same Member State largely similar or was there considerable interregional disparity?; (3) Were the relative contributions of efficiency change, technological change, and changes in physical and human capital accumulation to productivity growth more homogeneous or rather heterogeneous across NUTS 2-regions?; and (4) Was there a trend of convergence or rather one of divergence in regional productivity in the EU during the period 2000-2011. The results of the analyses suggest the following answers to the questions raised.

1. As to the first research question, results suggest that in spite of recent European programs such as the Lisbon Agenda and ESI-Funding, regional productivity growth has been relatively limited for the whole EU. This finding of limited growth confirms what was found by other studies for previous periods (Sala-i-Martin and Barro 1991). Results also indicated that changes in regional productivity has been rather "uneven". As to the old EU Member States, most regions in Denmark, Finland, Sweden, Germany, the Netherlands and Belgium experienced positive productivity growth whereas regions in the Southern EU Member States (i.e., Italy, Greece, Spain) mostly experienced regress in productivity. In the new EU Member States, a lot of regions in Croatia, the Czech Republic, Lithuania, Poland and Slovenia realized high to very high progress in productivity which enabled these regions to converge towards the regions in the North of Europe. On the other hand, most regions in Malta, Hungary, Bulgaria and Romania saw productivity declining in the period 2000-2011.

2. Detailed analyses of the regional productivity growth rates show considerable differences in the economic development and productivity of regions both between as well as within EU Member States. Based on the results, a possible explanation for the high within-country and between-country regional differences in productivity and economic development is the existence of interregional differences in the available mix of production factors (labour, physical capital and human capital).

3. The quadripartite decomposition of the regional productivity growth rates indicated that, in general, changes in efficiency predominantly deteriorated regional productivity, technological change had little or no effect on regional productivity, and changes in physical and human capital accumulation contributed positively to regional productivity growth. One possible explanation for the insignificant contribution of technological change could be the impact of the financial and economic crisis with investments in innovation slowing down in almost all EU Member States since 2008. Archibugi and Filippetti (2011), for instance, demonstrated that whereas there was a trend of progress and convergence in innovative potential in the EU during the years leading up to the economic crisis, innovative investments have slowed down in almost all EU Member States since 2008, with the negative impact on innovative investment particularly affecting catch-up Member States and regions. The net result may well be stagnation of technological contribution to productivity growth for the whole EU over the period 2000-2011. 
4. The negative and non-significant contribution of respectively efficiency change and technological change to regional productivity growth was more or less homogeneous across regions. The positive contributions of changes in physical and human capital accumulation to regional productivity growth were also observed among most regions, though, with important interregional differences in magnitude of the contributions. In particular, changes in physical capital accumulation were found to benefit principally the productivity of the regions that were least productive in 2000. On the other hand, changes in human capital accumulation appeared to be an important driving force behind the evolution in regional productivity in the regions that were initially among the most productive (particularly regions located in the centre of Germany, Benelux countries and Scandinavia as well as Southern regions in the UK).

5. As to the question of whether there was convergence, the finding of multimodality in the distribution of regional productivity provides supports to the notion of club convergence (Galor 1996) in which groups of regions are evolving towards multiple equilibria, i.e., rich and developed regions (mostly regions in Denmark, Finland, Sweden, Germany, the Netherlands and Belgium) evolving towards a high productivity equilibrium and poor and less-developed (mostly regions in Southern EU Member States and some of the Central and Eastern EU Member States) regions evolving towards an equilibrium of low productivity. Overall, the findings confirm what was found by previous (parametric) studies (Quah 1996; Crespo Cuaresma et al. 2014; De Siano and D'Uva 2006), i.e. a process of slow yet robust convergence across regions in Europe and the existence of convergence poles at the regional level in Europe.

Nevertheless, some caveats to the present study need to be emphasized. First, an important question is whether the assumption upheld in the present study of the technology frontier being uniform for all EU NUTS 2-regions is valid and realistic. Several theoretical papers such as Acemoglu and Zilibotti (2001) and Basu and Weil (1998) have raised doubts with the assumption of production technology being more or less homogeneous across economies. Their reasoning is that the technology frontier is not uniform in the sense that not all existing production technologies are equally well-matched to every economy. Basu and Weil (1998), for instance, argued that the implementation of new innovative technology is typically capitalintensive which makes it often difficult for economies with low capital endowments to adopt new technology. In addition, several empirical studies demonstrated that background conditions may hamper or benefit regional productivity. Examples of background conditions include the presence of a capital city (Crespo Cuaresma et al. 2014), local institutions (Acemoglu and Dell 2010), physical location (Quah 1996), etc. All of this suggests that the assumption of the production technology frontier being uniform across (groups of) regions in the EU should at least be further examined and tested.

Another caveat concerns the possible spatial correlation in the regional economic data (due to for instance knowledge spill-overs or national government policies). As noted by Crespo Cuaresma et al. (2014), the issue of spatial correlation is much more pervasive in models of regional economic growth than in studies of country-level economic growth. An interesting topic for further research would be to examine productivity growth among European NUTS 2- 
regions using nonparametric production frontier techniques similar to the one in the present paper, thereby accounting for the spatial correlation between the regions. 


\section{Literature}

Acemoglu D, Dell M (2010) Productivity differences between and within countries. American Economic Journal: Macroeconomics 2(1): 169-88.

Acemoglu D, Zilibotti F (2001) Productivity differences. Quarterly Journal of Economics 116(2): 563-606.

Afriat SN (1972) Efficiency estimation of production functions. International Economic Review: 568-598.

Archibugi D, Filippetti A (2011) Is the economic crisis impairing convergence in innovation performance across Europe? JCMS: Journal of Common Market Studies 49(6): 1153-1182.

Azomahou TT, El ouardighi J, Nguyen-Van P, Pham TKC (2011) Testing convergence of European regions: A semiparametric approach. Economic Modelling 28(3): 1202-1210.

Badunenko O, Henderson DJ, Russell RR (2013) Polarization of the worldwide distribution of productivity. Journal of Productivity Analysis: 40(2) 153-171.

Bartkowska M, Riedl A (2012) Regional convergence clubs in Europe: Identification and conditioning factors. Economic Modelling 29(1): 22-31.

Basu S, Weil DN (1998) Appropriate technology and growth. Quarterly Journal of Economics 113(4): 1025-1054.

Battisti M, De Vaio G (2008) A spatially filtered mixture of $\beta$-convergence regressions for EU regions, 1980-2002. Empirical Economics 34(1): 105-121.

Becker SO, Egger PH, Van Ehrlich M (2010) Going NUTS: the effect of EU Structural Funds on regional performance. Journal of Public Economics 94: 578-590.

Becker SO, Egger PH, Ehrlich MV (2016) Effects of EU Regional Policy: 1989-2013. University of Warwick Department of Economics Working Paper No. 1118.

Beugelsdijk S, Klasing M, Milionis P (2015) Regional TFP Differences in Europe and What We Can Learn from Them. Mimeo.

Canova F (2004) Testing for convergence clubs in income per capita: a predictive density approach. International Economic Review 45: 49-77.

Cazals C, Florens JP, Simar L (2002) Nonparametric frontier estimation: a robust approach. Journal of Econometrics 106(1): 1-25.

Charnes A, Cooper WW, Rhodes E (1978) Measuring the efficiency of decision making units. European Journal of Operational Research 2(6): 429-444.

Christopoulos DK, Tsionas EG (2007) Are regional incomes in the USA converging? A non-linear perspective. Regional Studies 41(4): 525-530.

Crespo Cuaresma J, Doppelhofer G, Feldkircher M (2014) The determinants of economic growth in European regions. Regional Studies 48(1): 44-67.

De Siano R, D’Uva M (2006) Club convergence in European regions. Applied Economics Letters 13(9): 569-574.

Delgado-Rodríguez MJ, Álvarez-Ayuso I (2008) Economic growth and convergence of EU member states: an empirical investigation. Review of Development Economics 12(3): 486-497. 
Diewert WE (1980) Capital and the theory of productivity measurement. The American Economic Review/ 260-267.

Drivas K, Economidou C, Tsionas EG (2017) Production of output and ideas: efficiency and growth patterns in the United States. Regional Studies: 1-14.

Durlauf SN, Quah DT (1999) The new empirics of economic growth. Handbook of Macroeconomics 1: 235-308.

Epstein L, Denny M (1980) Endogenous capital utilization in a short-run production model: Theory and an empirical application. Journal of Econometrics 12(2): 189-207.

European Commission (2014) Investment for growth and jobs: Promoting development and good governance in EU regions and cities. Sixth report on economic, social and territorial cohesion.

Fan Y, Ullah A (1999) On goodness-of-fit tests for weakly dependent processes using kernel method. Journal of Nonparametric Statistics 11(1-3): 337-360.

Färe R, Grosskopf S, Norris M, Zhang Z (1994) Productivity growth, technical progress, and efficiency change in industrialized countries. The American Economic Review: 66-83.

Farrell MJ (1957) The measurement of productive efficiency. Journal of the Royal Statistical Society. Series A (General): 253-290.

Feldstein MS, Foot DK (1971) The other half of gross investment: Replacement and modernization expenditures. The Review of Economics Statistic: 49-58.

Fried HO, Lovell CK, Schmidt SS (Eds.) (2008) The measurement of productive efficiency and productivity growth. Oxford University Press.

Galor O (1996) Convergence? Inferences from theoretical models. The Economic Journal: 10561069.

Gitto S, Mancuso P (2015) The contribution of physical and human capital accumulation to Italian regional growth: a nonparametric perspective. Journal of Productivity Analysis 43: 1-12.

Hall RE, Jones CI (1999) Why do some countries produce so much more output per worker than others?. National bureau of economic research (NBER) (No. w6564).

Hall P, York M (2001) On the calibration of Silverman's test for multimodality. Statistica Sinica 11(2): 515-536.

Henderson DJ, Russell RR (2005) Human Capital and Convergence: A Production-Frontier Approach. International Economic Review 46(4): 1167-1205.

Hjalmarsson L, Kumbhakar SC, Heshmati A (1996) DEA, DFA and SFA: a comparison. Journal of Productivity Analysis 7(2): 303-327.

Juessen F (2009) A distribution dynamics approach to regional GDP convergence in unified Germany. Empirical Economics 37(3): 627-652.

Koopmans TC (1951) Analysis of production as an efficient combination of activities. In: Koopmans T.C. (ed) Activity analysis of production and allocation, Wiley, New York, pp 33-97.

Krüger JJ (2003) The global trends of total factor productivity: evidence from the nonparametric Malmquist index approach. Oxford Economic Papers 55(2): 265-286. 
Kumar S, Russell RR (2002) Technological change, technological catch-up, and capital deepening: relative contributions to growth and convergence. American Economic Review: 527-548.

Kumbhakar SC, Sun K (2012) Estimation of TFP growth: a semiparametric smooth coefficient approach. Empirical Economics 43(1): 1-24.

Kumbhakar SC, Wang HJ (2005) Estimation of growth convergence using a stochastic production frontier approach. Economics Letters 88(3): 300-305.

Kutan AM, Yigit TM (2007) European integration, productivity growth and real convergence. European Economic Review 51(6): 1370-1395.

Li Q (1996) Nonparametric testing of closeness between two unknown distribution functions. Econometric Reviews 15(3): 261-274.

Li Q, Maasoumi E, Racine JS (2009) A nonparametric test for equality of distributions with mixed categorical and continuous data. Journal of Econometrics 148(2): 186-200.

Mankiw NG, Romer D, Weil DN (1992) A Contribution to the Empirics of Economic Growth. The Quarterly Journal of Economics 107(2): 407-437.

Neven D, Gouymte C (1995) Regional convergence in the European Community. JCMS: Journal of Common Market Studies 33(1): 47-65.

Quah DT (1996) Regional convergence clusters across Europe. European Economic Review 40(3): 951-958.

Sala-i-Martin X, Barro RJ (1991) Convergence across states and regions. Economic Growth Center. Yale University.

Silverman BW (1981) Using kernel density estimates to investigate multimodality. Journal of the Royal Statistical Society. Series B (Methodological): 97-99.

Tsionas EG (2000) Regional growth and convergence: evidence from the United States. Regional Studies 34(3): 231-238.

Tsionas EG (2001) Regional convergence and common, stochastic long-run trends: a re-examination of the US regional data. Regional Studies 35(8): 689-696. 
Figure 1: Best practice EU production technology frontier 2000 vs. 2011 (sequential version)
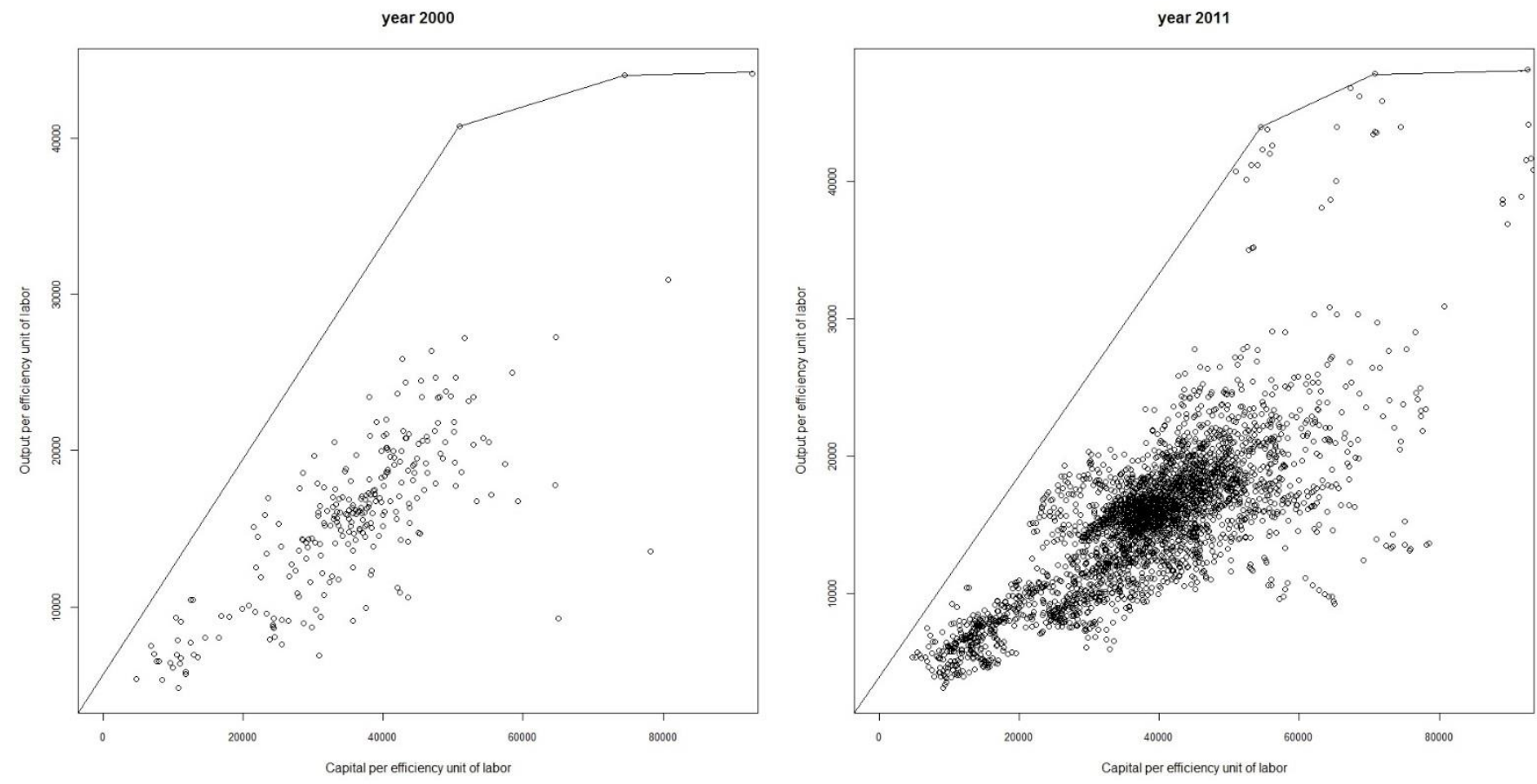

Figure 2: Kernel distributions of regional productivity and efficiency in 2000 vs. 2011
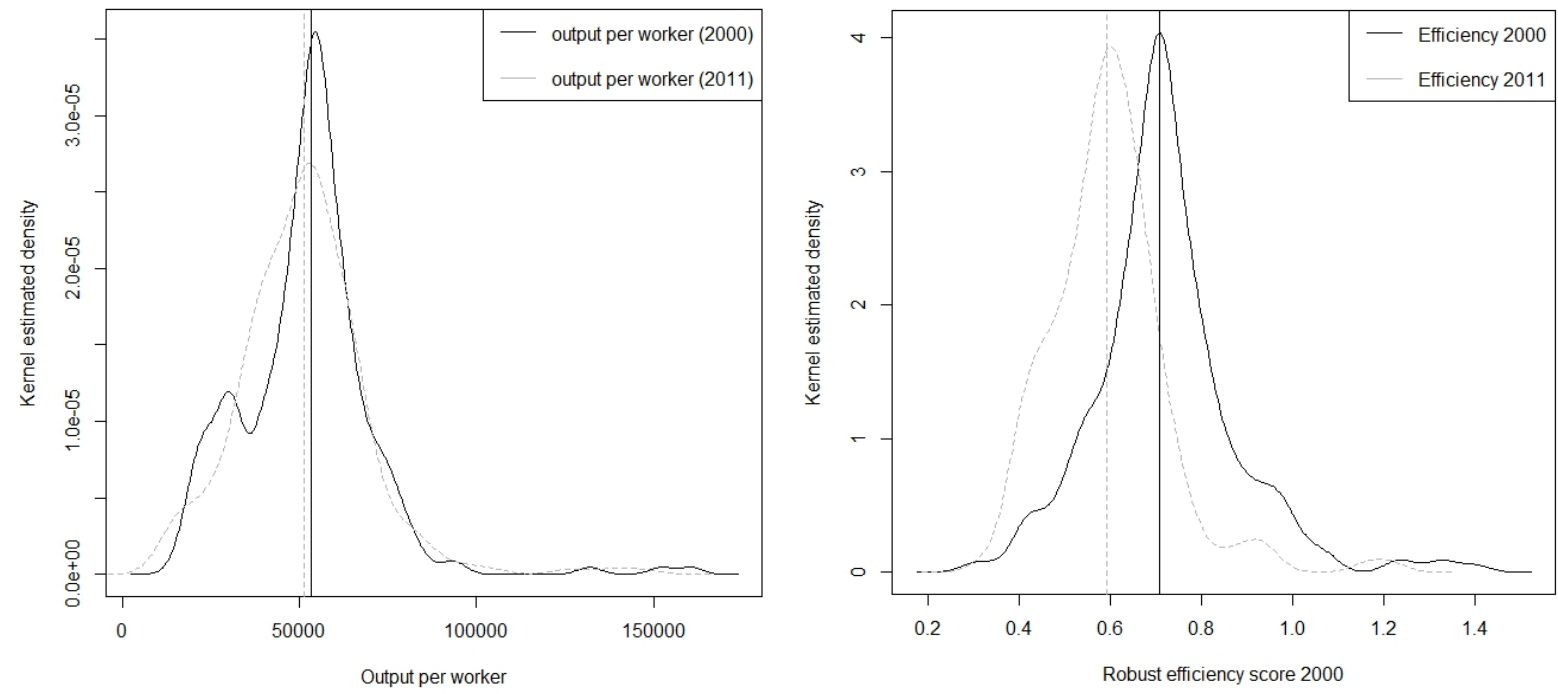
Figure 3: Productivity in 2000 vs. TFP-component indices (robust versions)

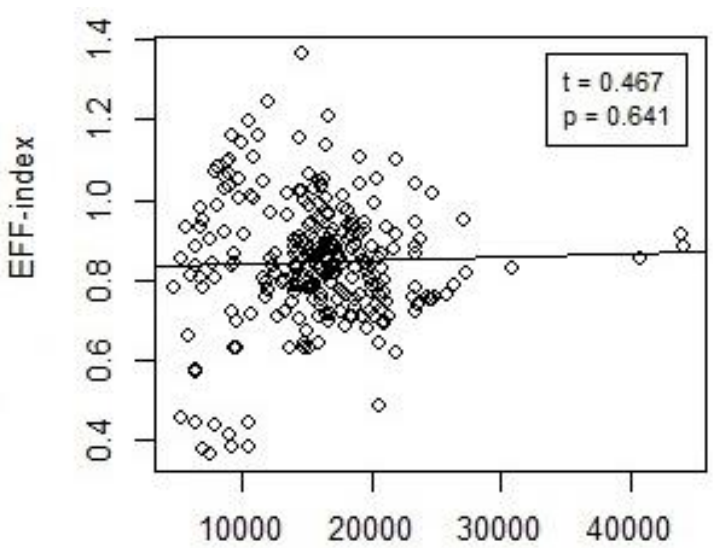

Output per worker in 2000

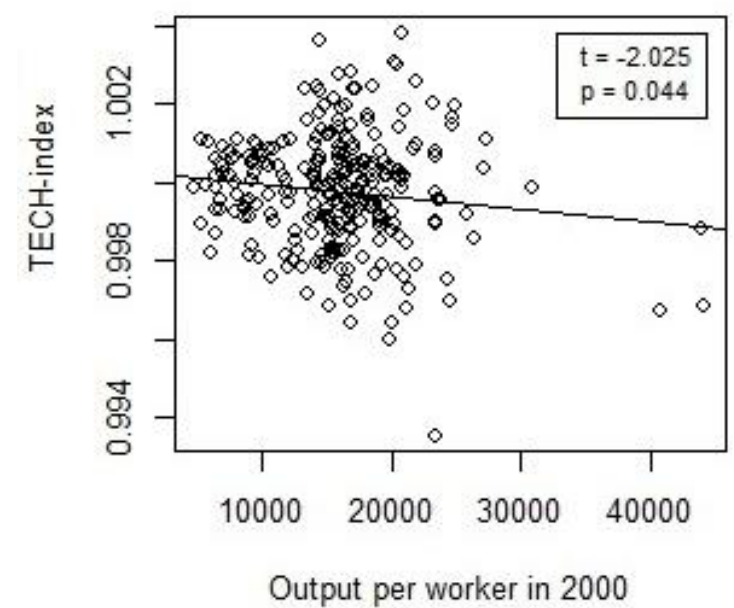

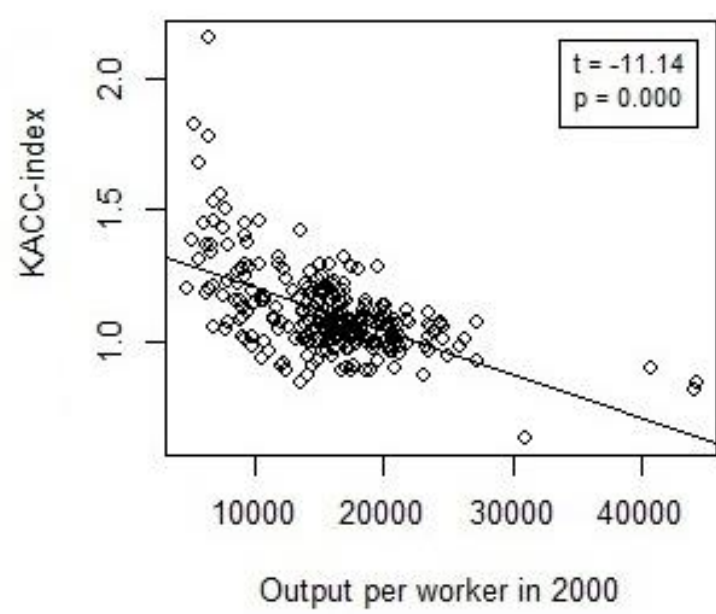

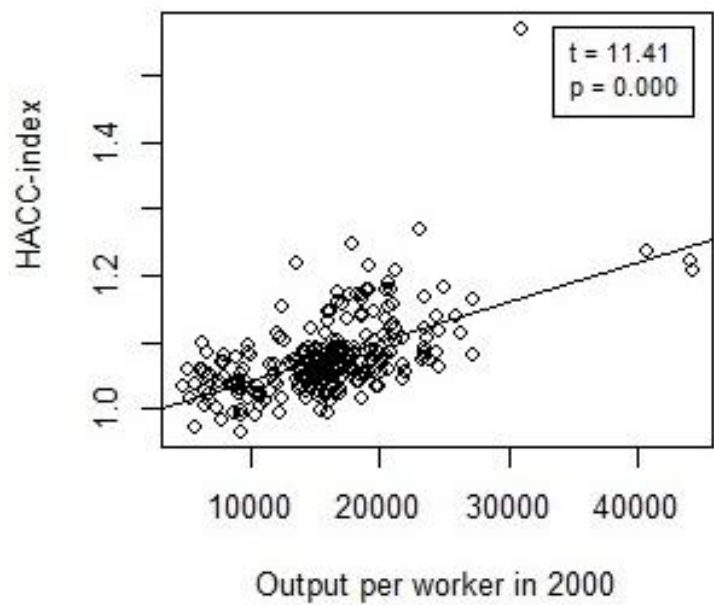


Table 1: Productivity growth and components (percentage changes)

\begin{tabular}{|c|c|c|c|c|c|}
\hline Member State & (TFP-1) x 100 & $(E F F-1) \times 100$ & (TECH-1) x 100 & $($ KACC-1) x 100 & $(\mathrm{HACC}-1) \times 100$ \\
\hline Austria & 0.56 & -16.39 & -0.09 & 11.93 & 7.73 \\
\hline Belgium & -1.26 & -10.17 & 0.01 & -0.51 & 10.73 \\
\hline Denmark & 4.49 & -13.60 & -0.07 & 20.95 & 0.19 \\
\hline Finland & 9.82 & -15.40 & -0.05 & 23.63 & 5.24 \\
\hline France & -5.62 & -14.52 & -0.07 & 0.38 & 11.03 \\
\hline Germany & 14.72 & 2.46 & 0.04 & 7.40 & 4.58 \\
\hline Greece & -10.16 & -30.38 & -0.07 & 22.27 & 5.79 \\
\hline Ireland & 11.72 & -5.75 & -0.10 & 1.70 & 16.68 \\
\hline Italy & -12.86 & -24.32 & -0.08 & 5.16 & 9.85 \\
\hline Luxembourg & -4.92 & -14.63 & -0.33 & -9.60 & 23.61 \\
\hline Portugal & 2.56 & -16.58 & -0.09 & 13.68 & 9.74 \\
\hline Spain & -8.74 & -25.36 & 0.00 & 5.02 & 16.97 \\
\hline Sweden & 3.57 & -13.53 & 0.01 & 14.56 & 4.86 \\
\hline The Netherlands & 3.09 & -6.30 & 0.01 & 2.28 & 7.88 \\
\hline United Kingdom & -12.05 & -19.40 & 0.00 & 1.78 & 7.70 \\
\hline Old EU MS & -0.34 & -14.92 & -0.06 & 8.04 & 9.51 \\
\hline Bulgaria & -7.96 & -42.00 & 0.00 & 58.15 & 2.93 \\
\hline Croatia & 14.57 & 4.02 & -0.11 & 13.96 & -1.96 \\
\hline Czech Republic & 22.28 & 4.68 & -0.08 & 11.97 & 5.07 \\
\hline Estonia & 9.69 & -9.64 & 0.01 & 17.18 & 3.58 \\
\hline Hungary & -12.89 & -27.48 & -0.01 & 15.42 & 4.72 \\
\hline Latvia & 0.95 & -6.73 & -0.07 & 5.87 & 2.30 \\
\hline Lithuania & 51.97 & -6.63 & -0.01 & 67.37 & -2.75 \\
\hline Malta & -12.60 & -17.76 & 0.01 & -7.34 & 14.55 \\
\hline Poland & 22.69 & -10.05 & 0.00 & 29.04 & 7.00 \\
\hline Romania & -44.47 & -59.01 & 0.03 & 34.32 & 1.72 \\
\hline Slovakia & 33.63 & 15.19 & -0.07 & 8.58 & 6.77 \\
\hline Slovenia & -6.79 & -17.25 & -0.09 & 6.36 & 6.30 \\
\hline New EU MS & 5.92 & -14.39 & -0.03 & 21.74 & 4.19 \\
\hline EU-region & 2.79 & -14.66 & -0.05 & 14.89 & 6.85 \\
\hline
\end{tabular}


Table 2: Modality tests of the counterfactual distributions of output per worker (by stepwise introduction of TFP-components) (bootstrapping with 10,000 replications)

\begin{tabular}{|c|c|c|c|}
\hline & $\begin{array}{c}\mathrm{H}_{0}: 1 \text { mode } \\
\mathrm{H}_{1}: \geq 1 \text { mode }\end{array}$ & $\begin{array}{c}\mathrm{H}_{0}: 2 \text { modes } \\
\mathrm{H}_{1}: \geq 2 \text { modes }\end{array}$ & $\begin{array}{c}\mathrm{H}_{0}: 3 \text { modes } \\
\mathrm{H}_{1}: \geq 3 \text { modes }\end{array}$ \\
\hline & p-value & p-value & p-value \\
\hline$f\left(\mathrm{y}_{2011}\right)$ & 0.000 & 0.112 & 0.477 \\
\hline$f\left(\mathrm{y}_{2000}\right)$ & 0.023 & 0.003 & 0.254 \\
\hline$f\left(\mathrm{y}_{2000} \quad \mathrm{x} \mathrm{EFF}\right)$ & 0.000 & 0.146 & 0.553 \\
\hline$f\left(\mathrm{y}_{2000} \times \mathrm{TECH}\right)$ & 0.020 & 0.004 & 0.260 \\
\hline$f\left(\mathrm{y}_{2000} \times \mathrm{KACC}\right)$ & 0.002 & 0.001 & 0.085 \\
\hline$f\left(\mathrm{y}_{2000} \times \mathrm{HACC}\right)$ & 0.141 & 0.010 & 0.350 \\
\hline$f\left(\mathrm{y}_{2000} \times \mathrm{EFF} \times \mathrm{TECH}\right)$ & 0.000 & 0.152 & 0.581 \\
\hline$f\left(\mathrm{y}_{2000} \times \mathrm{EFF} \times \mathrm{KACC}\right)$ & 0.000 & 0.058 & 0.480 \\
\hline$f\left(\mathrm{y}_{2000} \times \mathrm{EFF} \times \mathrm{HACC}\right)$ & 0.000 & 0.356 & 0.025 \\
\hline$f\left(\mathrm{y}_{2000} \times \mathrm{TECH} \times \mathrm{KACC}\right)$ & 0.002 & 0.002 & 0.085 \\
\hline$f\left(\mathrm{y}_{2000} \times \mathrm{TECH} \times \mathrm{HACC}\right)$ & 0.133 & 0.013 & 0.341 \\
\hline$f\left(\mathrm{y}_{2000} \times \mathrm{KACC} \times \mathrm{HACC}\right)$ & 0.025 & 0.013 & 0.250 \\
\hline$f\left(\mathrm{y}_{2000} \times \mathrm{EFF} \times \mathrm{TECH} \times \mathrm{KACC}\right)$ & 0.000 & 0.058 & 0.469 \\
\hline$f\left(\mathrm{y}_{2000} \times \mathrm{EFF} \times \mathrm{TECH} \times \mathrm{HACC}\right)$ & 0.000 & 0.352 & 0.024 \\
\hline$f\left(\mathrm{y}_{2000} \times \mathrm{TECH} \times \mathrm{KACC} \times \mathrm{HACC}\right)$ & 0.017 & 0.000 & 0.247 \\
\hline$f\left(\mathrm{y}_{2000} \times \mathrm{EFF} \times \mathrm{TECH} \times \mathrm{KACC} \times \mathrm{HACC}\right)$ & 0.000 & 0.065 & 0.446 \\
\hline
\end{tabular}

Modality tests are performed by the bootstrapped Silverman test for multi-modality with 10,000 bootstrap replications.

Table 3: Distribution hypothesis test (bootstrapping with 10,000 replications)

\begin{tabular}{|c|c|c|}
\hline Null hypothesis $\left(\mathrm{H}_{0}\right)$ & $\begin{array}{l}\mathrm{T}_{\mathrm{n}} \text { Statistic } \\
\end{array}$ & $\begin{array}{c}\text { Bootstrap } \\
\text { p-value }\end{array}$ \\
\hline$f\left(\mathrm{y}_{2011}\right)=g\left(\mathrm{y}_{2000}\right)$ & 2.863 & 0.024 \\
\hline$f\left(\mathrm{y}_{2011}\right)=g\left(\mathrm{y}_{2000} \times \mathrm{EFF}\right)$ & 13.852 & 0.000 \\
\hline$f\left(\mathrm{y}_{2011}\right)=g\left(\mathrm{y}_{2000} \times \mathrm{TECH}\right)$ & 15.919 & 0.000 \\
\hline$f\left(\mathrm{y}_{2011}\right)=g\left(\mathrm{y}_{2000} \times \mathrm{KACC}\right)$ & 4.469 & 0.001 \\
\hline$f\left(\mathrm{y}_{2011}\right)=g\left(\mathrm{y}_{2000} \times \mathrm{HACC}\right)$ & -0.639 & 0.079 \\
\hline$f\left(\mathrm{y}_{2011}\right)=g\left(\mathrm{y}_{2000} \times \mathrm{EFF} \times \mathrm{TECH}\right)$ & 24.971 & 0.000 \\
\hline$f\left(\mathrm{y}_{2011}\right)=g\left(\mathrm{y}_{2000} \times \mathrm{EFF} \times \mathrm{KACC}\right)$ & 2.608 & 0.168 \\
\hline$f\left(\mathrm{y}_{2011}\right)=g\left(\mathrm{y}_{2000} \times\right.$ EFF $\times$ HACC $)$ & -2.708 & 0.225 \\
\hline$f\left(\mathrm{y}_{2011}\right)=g\left(\mathrm{y}_{2000} \times\right.$ TECH $\times$ KACC $)$ & 15.617 & 0.000 \\
\hline$f\left(\mathrm{y}_{2011}\right)=g\left(\mathrm{y}_{2000} \times \mathrm{TECH} \times\right.$ HACC $)$ & -0.597 & 0.078 \\
\hline$f\left(\mathrm{y}_{2011}\right)=g\left(\mathrm{y}_{2000} \times \mathrm{KACC} \times \mathrm{HACC}\right)$ & 4.665 & 0.002 \\
\hline$f\left(\mathrm{y}_{2011}\right)=g\left(\mathrm{y}_{2000} \times\right.$ EFF $\times$ TECH $\times$ KACC $)$ & 25.621 & 0.000 \\
\hline$f\left(\mathrm{y}_{2011}\right)=g\left(\mathrm{y}_{2000} \times \mathrm{EFF} \times \mathrm{TECH} \times \mathrm{HACC}\right)$ & -2.703 & 0.226 \\
\hline$f\left(\mathrm{y}_{2011}\right)=g\left(\mathrm{y}_{2000} \times \mathrm{TECH} \times \mathrm{KACC} \times \mathrm{HACC}\right)$ & 2.981 & 0.120 \\
\hline$f\left(\mathrm{y}_{2011}\right)=g\left(\mathrm{y}_{2000} \times\right.$ EFF $\times$ TECH $\times$ KACC $\times$ HACC $)$ & -1.114 & 1.000 \\
\hline
\end{tabular}

The functions $f($.$) and g($.$) are kernel distribution functions (after Li, Maasoumi and Racine, 2009).$ 